\title{
Management of Transjugular Intrahepatic Portosystemic Shunt (TIPS)-associated Refractory Hepatic Encephalopathy by Shunt Reduction Using the Parallel Technique: Outcomes of a Retrospective Case Series
}

\author{
Daniel T. Cookson $\cdot$ Zubayr Zaman • \\ James Gordon-Smith • Hamish M. Ireland • \\ Peter C. Hayes
}

Received: 21 January 2010/Accepted: 9 September 2010/Published online: 6 November 2010

(C) Springer Science+Business Media, LLC and the Cardiovascular and Interventional Radiological Society of Europe (CIRSE) 2010

\begin{abstract}
Purpose To investigate the reproducibility and technical and clinical success of the parallel technique of transjugular intrahepatic portosystemic shunt (TIPS) reduction in the management of refractory hepatic encephalopathy (HE).

Materials and Methods A 10-mm-diameter self-expanding stent graft and a 5-6-mm-diameter balloon-expandable stent were placed in parallel inside the existing TIPS in 8 patients via a dual unilateral transjugular approach. Changes in portosystemic pressure gradient and HE grade were used as primary end points.

Results TIPS reduction was technically successful in all patients. Mean \pm standard deviation portosystemic pressure gradient before and after shunt reduction was $4.9 \pm$ $3.6 \mathrm{mmHg}$ (range, $0-12 \mathrm{mmHg}$ ) and $10.5 \pm 3.9 \mathrm{mmHg}$ (range, 6-18 mmHg). Duration of follow-up was $137 \pm$ 117.8 days (range, 18-326 days). Clinical improvement of HE occurred in 5 patients (62.5\%) with resolution of HE in 4 patients $(50 \%)$. Single episodes of recurrent gastrointestinal hemorrhage occurred in 3 patients $(37.5 \%)$. These were self-limiting in 2 cases and successfully managed in 1 case by correction of coagulopathy and blood transfusion.
\end{abstract}

D. T. Cookson · Z. Zaman · J. Gordon-Smith · H. M. Ireland Departments of Radiology, Royal Infirmary,

Little France, Edinburgh EH16 4SA, Scotland, UK

D. T. Cookson ( $₫)$

Department of Radiology, Middlemore Hospital, Hospital Road, Otahuhu, Auckland 1640, New Zealand

e-mail: danielthomascookson@yahoo.co.uk

P. C. Hayes

Departments of Hepatology, Royal Infirmary,

Little France, Edinburgh EH16 4SA, Scotland, UK

e-mail: p.hayes@ed.ac.uk
Two of these patients (25\%) died, one each of renal failure and hepatorenal failure.

Conclusion The parallel technique of TIPS reduction is reproducible and has a high technical success rate. A dual unilateral transjugular approach is advantageous when performing this procedure. The parallel technique allows repeat bidirectional TIPS adjustment and may be of significant clinical benefit in the management of refractory HE.

Keywords Interventional radiology $\cdot$ Hepatic encephalopathy $\cdot$ Transjugular intrahepatic portosystemic shunt

\section{Introduction}

Hepatic encephalopathy (HE) is a common complication of transjugular intrahepatic portosystemic shunt (TIPS) procedures, with reported incidences of 5-35\% [1]. TIPSassociated HE refractory to medical therapy occurs in $3-7 \%$ of patients [2]. Treatment options in this setting include liver transplantation, TIPS reduction or occlusion, and embolization of splenorenal portosystemic shunts. Multiple TIPS-directed procedures have been described and are associated with different advantages and disadvantages in terms of their potential reversibility and risk of adverse outcomes [3-10]. TIPS reduction by parallel placement of a self-expanding stent graft and a balloonexpandable stent inside an existing TIPS allows bidirectional adjustment of shunt diameter and portosystemic pressure gradient (PSPG), thereby optimizing control of TIPS configuration and flow. Repeat bidirectional TIPS adjustment is also feasible using this method [9]. These advantages are not conferred by alternative TIPS reduction procedures that use stent grafts $[7,8,10,11]$. Published 
experience of the parallel technique is, however, limited to a small number of case reports and case series $[4-6,9]$. To our knowledge, this study is the second largest to date of the parallel technique and comprises the largest reported experience of its accomplishment via a solely transjugular approach. The reproducibility of this procedure and its technical and clinical success were investigated by means of changes in PSPG and HE grade as primary end points.

\section{Materials and Methods}

\section{Patient Selection}

Institutional review board approval was not required for this retrospective audit. Eight patients (7 men, 1 woman; mean \pm standard deviation $[\mathrm{SD}]$ age, $57.1 \pm 7.7$ years; age range $45-70$ years) underwent TIPS reduction using the parallel technique between January 5, 2008, and January 21,2009 . The median interval from TIPS creation to TIPS reduction was 509.6 days (range, 16-730 days). TIPS creation was performed in a total of 61 patients during this period. All patients were referred after hepatology assessment by a specialist. Child-Pugh scores at the time of initial patient referral were $\mathrm{B}(n=3 ; 37.5 \%)$ and $\mathrm{C}(n=5$; $62.5 \%$ ). The indication for TIPS reduction was HE refractory to medical treatment. HE at the time of initial patient referral was classified as grade I $(n=1 ; 12.5 \%)$, grade II $(n=3 ; 37.5 \%)$, grade III $(n=2 ; 25 \%)$, and grade IV $(n=2 ; 25 \%)$ according to West Haven criteria [12] (Table 1). Medical treatment of HE included regular oral administration of lactulose $(n=8 ; 100 \%)$ and neomycin $(n=4 ; 50 \%)$ supplemented in one patient with administration of phosphate enemas as appropriate. Upper gastrointestinal endoscopy was performed during the admission period in all patients with a history of variceal hemorrhage

Table 1 West Haven criteria for classification of HE

\begin{tabular}{ll}
\hline Grade & Description \\
\hline I & Trivial lack of awareness \\
& Euphoria or anxiety \\
& Shortened attention span \\
& Impaired performance of addition \\
& Lethargy or apathy \\
II & Minimal disorientation for time and place \\
& Subtle personality change \\
& Inappropriate behavior \\
& Impaired performance of subtraction \\
& Somnolence to semistupor, responsive to verbal stimuli \\
III & Gross disorientation \\
IV & Coma (unresponsive to verbal or noxious stimuli) \\
\hline
\end{tabular}

$(n=6 ; 75 \%)$. Prophylactic treatment by banding was also carried out at this time if required.

TIPS was performed with 10-mm-diameter selfexpanding polytetrafluoroethylene-covered nitinol Viatorr stent grafts (W. L. Gore \& Associates, Flagstaff, AZ) postdilated to $10 \mathrm{~mm}$ in all patients. The mean \pm SD PSPG before and after TIPS creation was $20.2 \pm 8.6 \mathrm{mmHg}$ (range, $10-37 \mathrm{mmHg}$ ) and $4.5 \pm 3.4 \mathrm{mmHg}$ (range, $0-10$ $\mathrm{mmHg}$ ), respectively. The decrease in PSPG was $15.8 \pm$ $6.6 \mathrm{mmHg}$ (range, $5-27 \mathrm{mmHg}$ ).

\section{TIPS Reduction Procedure}

TIPS reduction was performed according to the technique described by Holden et al. [5] via the right $(n=7)$ or left $(n=1)$ internal jugular vein. The procedure was carried out in an angiography suite using local anesthesia in all patients and sedoanalgesia as required. Systemic venous pressure was recorded with a $40-\mathrm{cm} 10 \mathrm{~F}$ sheath (Cook, Bloomington, IN) placed within the right atrium. The TIPS was then accessed through the $10 \mathrm{~F}$ sheath with standard catheters and wires. TIPS angiography and portal venous pressure measurement were performed with a pigtail catheter (Fig. 1) and the initial PSPG recorded. The 10F sheath was then advanced through the TIPS into the portal vein. A 45-cm 6F Destination sheath (Terumo, Somerset, $\mathrm{NJ}$ ) was subsequently advanced through the TIPS into the portal vein via a second puncture of the ipsilateral internal

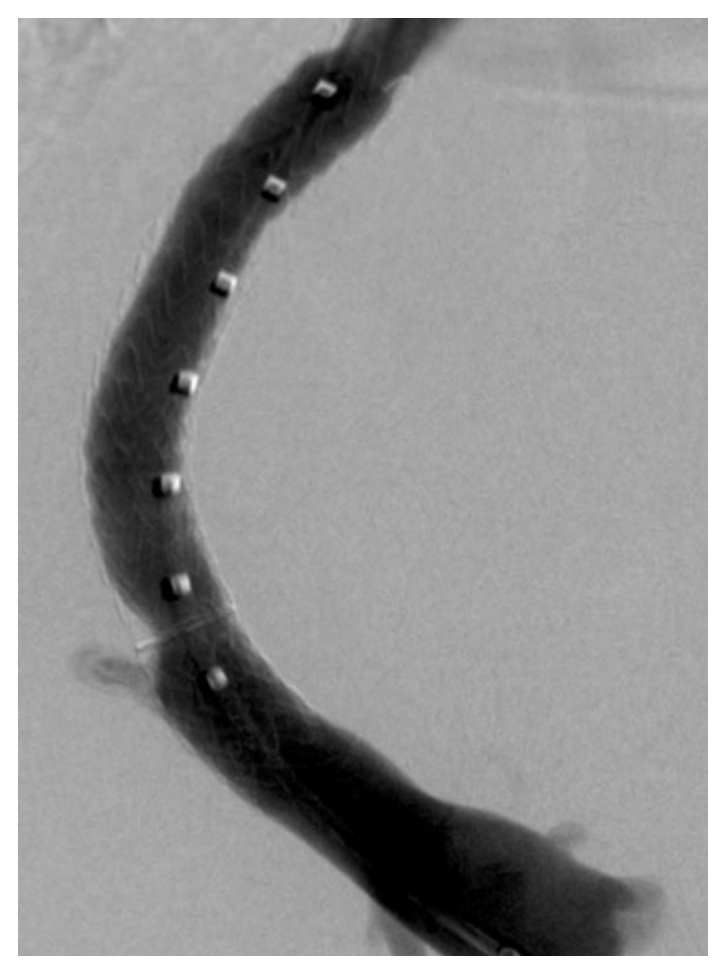

Fig. 1 TIPS angiogram demonstrating patent shunt 


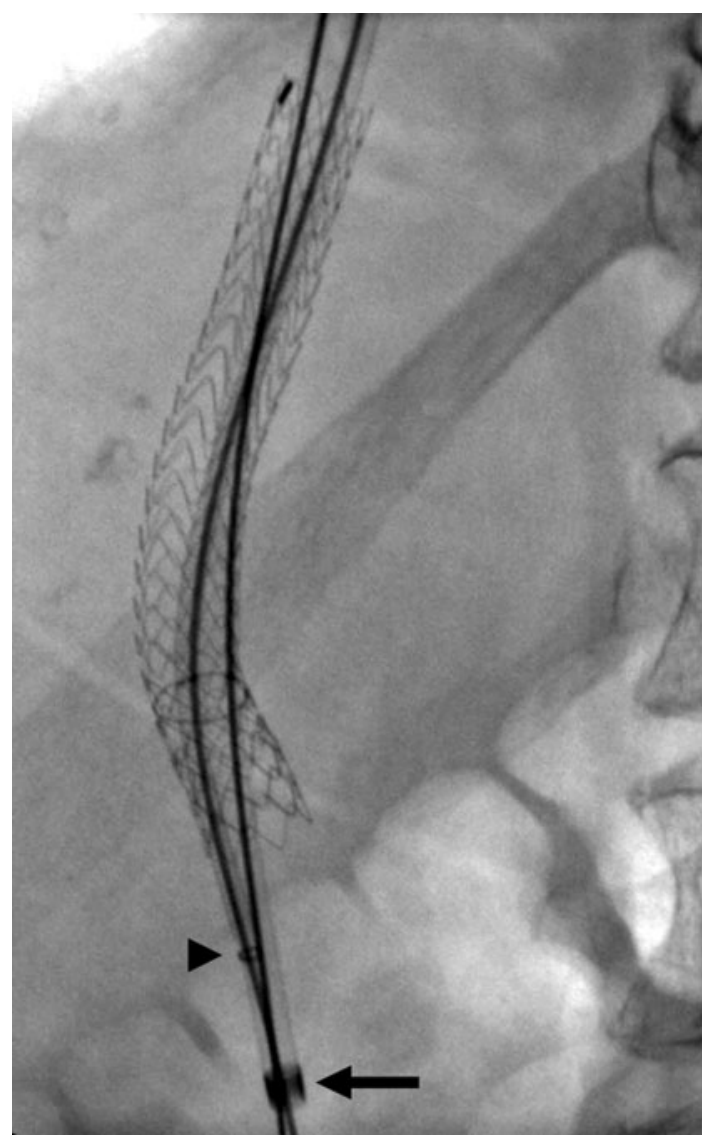

Fig. 2 Parallel placement of $10 \mathrm{~F}$ sheath (arrow) and $6 \mathrm{~F}$ sheath (arrowhead) within TIPS

jugular vein (Fig. 2). A short 5-mm-diameter $(n=5)$ or 6-mm-diameter $(n=3)$ balloon-expandable uncovered stent (Palmaz Blue; Cordis, Warren, NJ; Palmaz Genesis; Cordis) was then introduced through the $6 \mathrm{~F}$ sheath and positioned at the midpoint of the covered portion of the in situ Viatorr stent graft (Fig. 3). A 6-mm-diameter stent was used if a 5-mm stent was unavailable. A new 10-mmdiameter Viatorr stent graft was then introduced through the $10 \mathrm{~F}$ sheath over a stiff guide wire (Amplatz; Cook) and advanced until the radiopaque ring marking the junction of its covered and uncovered portions was level with the marker ring of the in situ stent graft. The $6 \mathrm{~F}$ sheath was then withdrawn into the right atrium to allow deployment of the balloon-expandable stent. The uncovered portion of the new stent graft was deployed by withdrawal of the $10 \mathrm{~F}$ sheath into the right atrium, maintaining superimposition of the ring markers of both stent grafts. The balloon-expandable stent was then dilated to its nominal diameter (Fig. 4), and the covered portion of the new stent graft was subsequently deployed with the angioplasty balloon still inflated (Fig. 5). The new stent graft was thereby focally narrowed at its midpoint by extrinsic compression from the balloonexpandable stent. Postreduction TIPS angiography was then

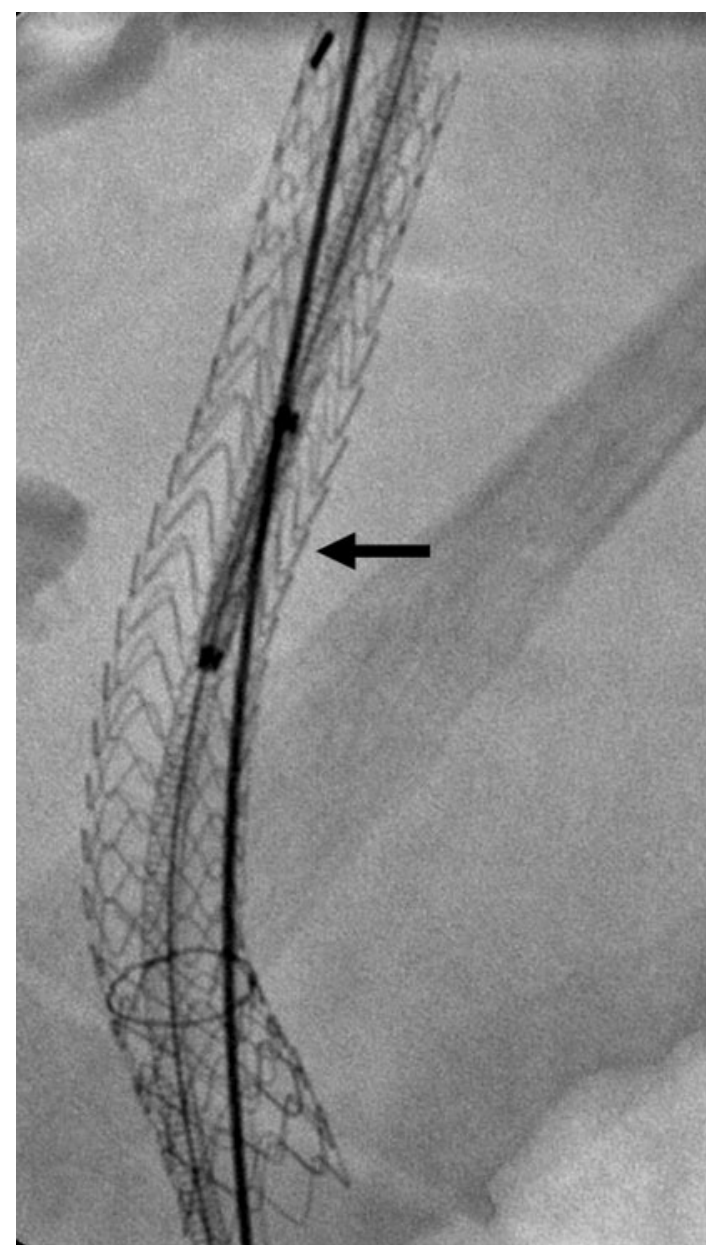

Fig. 3 Undeployed balloon-expandable stent (arrow) within 6F sheath at the midpoint of the covered portion of TIPS

performed to confirm patency of the narrowed shunt (Fig. 6), and the postreduction PSPG was recorded. The angioplasty balloon was subsequently deflated and removed. Hemostasis was achieved by manual compression of both puncture sites after sheath and guide wire removal.

\section{Follow-up}

Clinical follow-up was performed by the same hepatologists responsible for initial patient referral. Outcome data were obtained by combined retrospective review of case notes, the electronic hospital information system, and the radiology information system at our institution. The procedural angiograms at the time of TIPS reduction were also systematically reviewed for each patient.

\section{Study End Points}

Study end points were the technical and clinical success of the procedure. Technical success was defined as an increase in PSPG associated with correct placement of the 


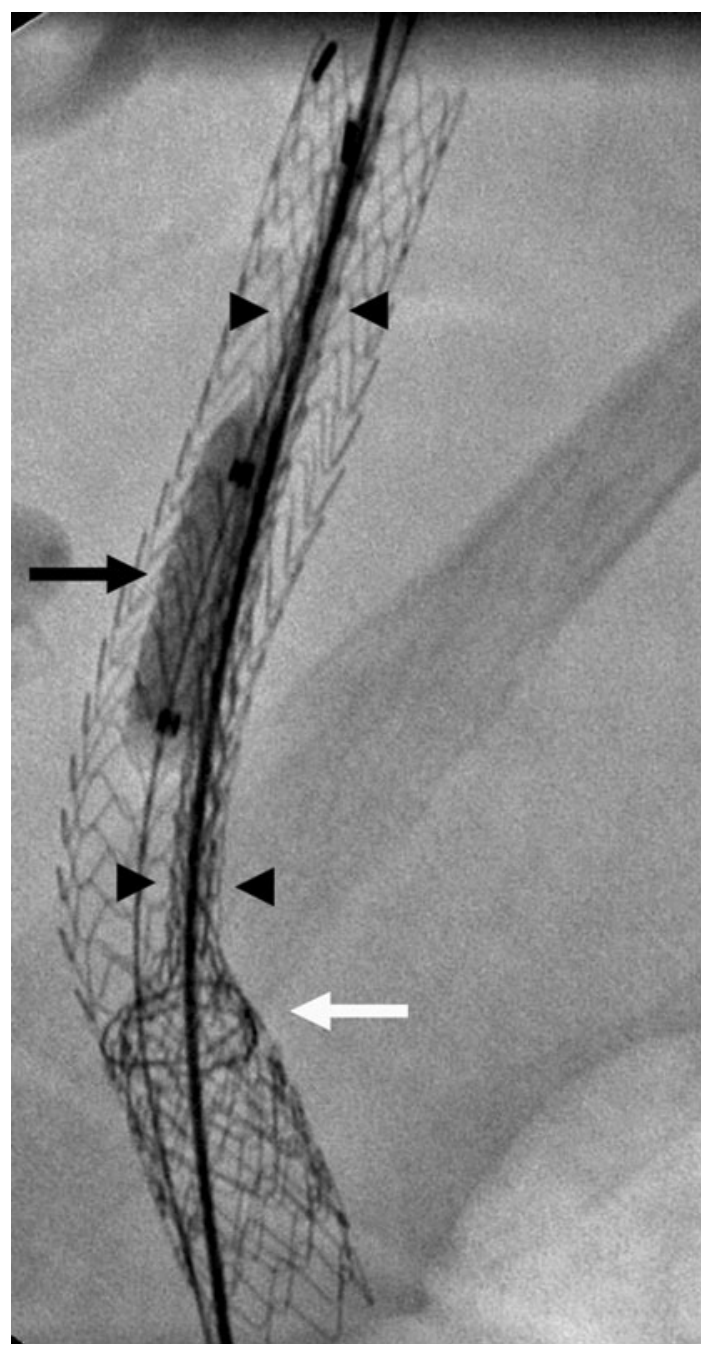

Fig. 4 Deployed uncovered portion of new stent graft (white arrow) and balloon-expandable stent (black arrow). The covered portion of the new stent graft (arrowheads) has not yet been deployed

stent graft and balloon-expandable stent in the absence of any immediate complications. Note was also made of any increase in intrahepatic portal perfusion immediately after TIPS reduction. This was determined by the presence of antegrade angiographic opacification of a greater length and/or number of intrahepatic portal vein branches in comparison with the preliminary angiogram. TIPS reduction was considered to be clinically successful if the worst $\mathrm{HE}$ grade at follow-up was better than the HE grade at the time of referral. Recurrence of gastrointestinal hemorrhage and any other adverse clinical events after TIPS reduction were also recorded.

\section{Results}

Patient and procedural data at the time of TIPS creation and TIPS reduction are summarized in Tables 2 and 3,

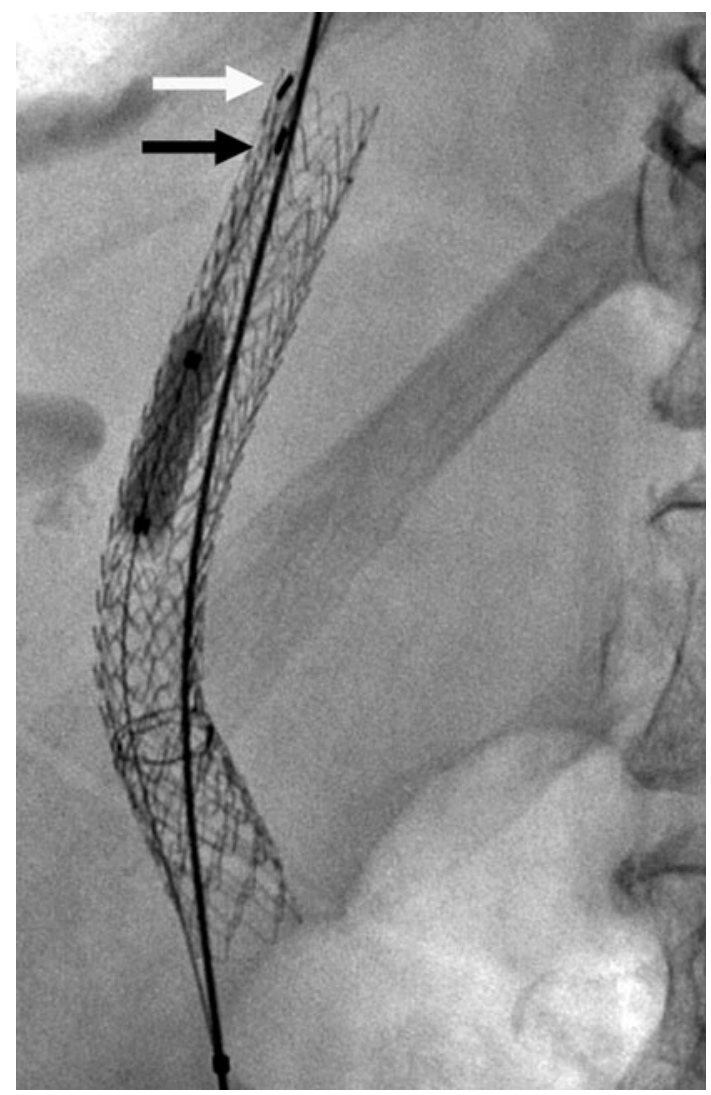

Fig. 5 Fully deployed new stent graft with lateral release of its proximal end (black arrow) toward the inner wall of the old stent graft (white arrow)

respectively. Technical and clinical outcomes of TIPS reduction are also recorded in Table 3.

\section{Technical Outcome}

TIPS reduction was technically successful in all patients. The mean \pm SD PSPG before and after shunt reduction was $4.9 \pm 3.6 \mathrm{mmHg}$ (range, $0-12 \mathrm{mmHg}$ ) and $10.5 \pm$ $3.9 \mathrm{mmHg}$ (range, 6-18 $\mathrm{mmHg}$ ) respectively. The increase in PSPG was $5.6 \pm 2.1 \mathrm{mmHg}$ (range, $2-8 \mathrm{mmHg}$ ). Intrahepatic portal vein perfusion increased in 3 patients (37.5\%). There was no clear correlation between changes in PSPG or intrahepatic portal vein perfusion and changes in $\mathrm{HE}$ grade. Opacification of portosystemic varices was noted in 1 patient $(12.5 \%)$ with a final PSPG of $6 \mathrm{mmHg}$. Variceal opacification was present before TIPS reduction in this case and did not significantly increase. Prophylactic embolization was not concurrently performed in this or any other patient.

\section{Clinical Outcome}

Mean \pm SD duration of follow-up was $137 \pm 117.8$ days (range, 18-326 days). Follow-up was performed to the end 


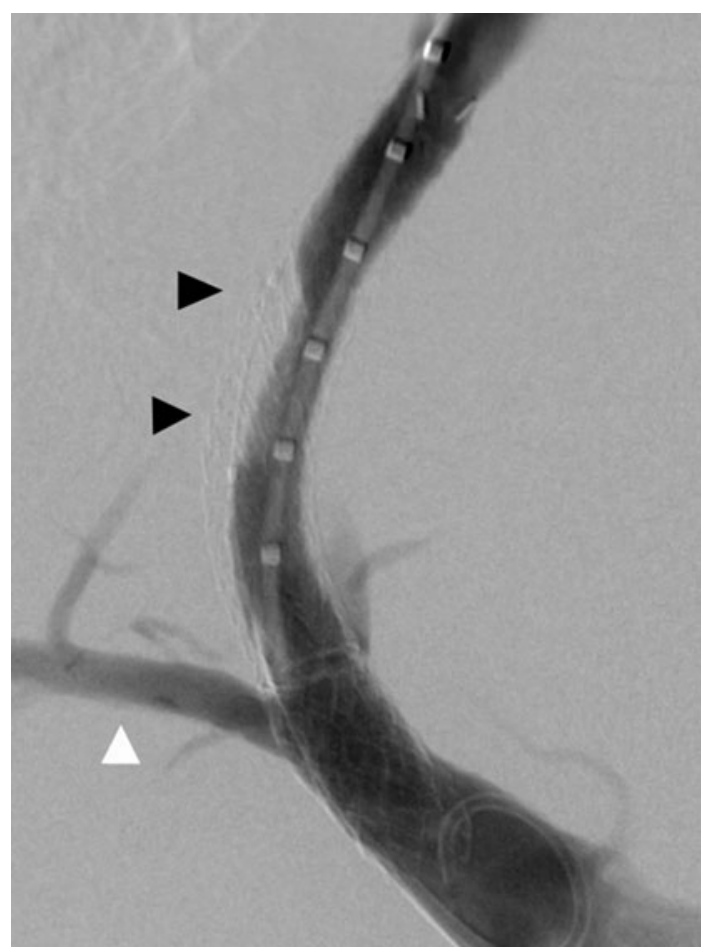

Fig. 6 TIPS angiogram demonstrating narrowed shunt (black arrowheads) and increased intrahepatic portal vein opacification (white arrowhead)

of the study period $(n=5)$, death $(\mathrm{n}=2)$, or liver transplantation $(n=1)$. Mean encephalopathy grade improved from 2.6 to 1.5. Clinical improvement of HE occurred in 5 patients $(62.5 \%)$, with resolution of $\mathrm{HE}$ in 4 patients $(50 \%)$ and partial improvement in 1 patient (12.5\%). No adverse clinical events occurred in patients in whom HE improved. $\mathrm{HE}$ failed to improve in 3 patients (37.5\%). Single episodes of recurrent gastrointestinal hemorrhage occurred in these
3 cases. These were self-limiting in 2 cases and successfully managed in 1 case by correction of coagulopathy and blood transfusion without endoscopic or TIPS reintervention. Two of these patients $(25 \%)$ died, one each of renal failure and hepatorenal failure. The mean \pm SD interval to time of death from TIPS reduction was $77 \pm 49.5$ days (range, 42-112 days).

\section{Discussion}

Endovascular treatment options for TIPS-associated HE refractory to medical therapy include TIPS reduction or occlusion and the embolization of splenorenal portosystemic shunts [3]. Splenorenal shunts are present in approximately $24 \%$ of patients with cirrhosis [3], although this was not observed in our study. TIPS reduction is safer than TIPS occlusion in the initial management of refractory HE [3, 12-16]. The intention of TIPS reduction is to narrow the shunt flow lumen while preserving its patency, potentially increasing hepatic detoxification of gut-derived nitrogenous compounds while maintaining TIPS function. This may be achieved by placement of a focally narrowed uncovered stent $[2,17,18]$ or a similarly configured stent graft [4-11] inside an existing TIPS. Reduction stent grafts are associated with better technical and clinical outcomes than uncovered stents [7]. Appropriate stent graft configuration may be achieved with a constraining suture [11] or concentric stent [7] or by proximal and distal balloon dilatation $[8,10]$. These methods are potentially reversible but are time-consuming and do not permit bidirectional adjustment of shunt diameter and PSPG. Techniques involving proximal and distal dilatation may also be subject to the risk of stent graft migration during deployment

Table 2 Patient and procedural characteristics at TIPS creation

\begin{tabular}{|c|c|c|c|c|c|}
\hline \multirow[t]{2}{*}{$\begin{array}{l}\text { Patient no./age } \\
\text { (y)/sex }\end{array}$} & \multirow[t]{2}{*}{ Cause of liver disease } & \multirow[t]{2}{*}{ Indication for TIPS } & \multirow[t]{2}{*}{ Stent graft } & \multicolumn{2}{|c|}{$\begin{array}{l}\text { PSPG } \\
(\mathrm{mmHg})\end{array}$} \\
\hline & & & & Pre & Post \\
\hline $1 / 52 / \mathrm{M}$ & $\begin{array}{l}\text { ALD and } \\
\text { hemochromatosis }\end{array}$ & Variceal hemorrhage & $10 \times 7+2 \mathrm{~cm}$ Viatorr & 28 & 6 \\
\hline $2 / 54 / \mathrm{M}$ & ALD & $\begin{array}{l}\text { Prophylactic decompression of varices before } \\
\text { esophagectomy }\end{array}$ & $10 \times 7+2 \mathrm{~cm}$ Viatorr & 18 & 3 \\
\hline $3 / 55 / \mathrm{M}$ & ALD & Variceal hemorrhage & $10 \times 7+2 \mathrm{~cm}$ Viatorr & 10 & 5 \\
\hline $4 / 64 / F$ & ALD & Variceal hemorrhage & $10 \times 8+2 \mathrm{~cm}$ Viatorr & 14 & 2 \\
\hline $5 / 53 / \mathrm{M}$ & ALD & Variceal hemorrhage & $10 \times 7+2 \mathrm{~cm}$ Viatorr & 21 & 8 \\
\hline 6/70/M & Cryptogenic cirrhosis & Refractory ascites & $\begin{array}{l}10 \times 8+2 \mathrm{~cm} 10 \times 6+2 \mathrm{~cm} \\
\text { Viatorr }^{\mathrm{a}}\end{array}$ & 16 & 0 \\
\hline $7 / 45 / \mathrm{M}$ & NAFLD & Variceal hemorrhage & $10 \times 8+2 \mathrm{~cm}$ Viatorr & 37 & 10 \\
\hline $8 / 59 / \mathrm{F}$ & ALD & Variceal hemorrhage & $10 \times 8+2 \mathrm{~cm}$ Viatorr & 18 & 2 \\
\hline
\end{tabular}

$A L D$ alcoholic liver disease, $N A F L D$ nonalcoholic fatty liver disease

a Overlapping stent grafts 
Table 3 Patient and procedural characteristics at TIPS reduction

\begin{tabular}{|c|c|c|c|c|c|c|c|c|c|}
\hline \multirow[t]{2}{*}{$\begin{array}{l}\text { Patient no./ } \\
\text { age }\end{array}$} & \multirow[t]{2}{*}{ Stent graft } & \multirow[t]{2}{*}{$\begin{array}{l}\text { Balloon-expandable } \\
\text { stent }\end{array}$} & \multicolumn{2}{|c|}{$\begin{array}{l}\text { PSPG } \\
(\mathrm{mmHg})\end{array}$} & \multirow[t]{2}{*}{$\begin{array}{l}\text { Technical } \\
\text { outcome }\end{array}$} & \multirow{2}{*}{$\begin{array}{l}\text { Intrahepatic } \\
\text { portal } \\
\text { vein perfusion }\end{array}$} & \multicolumn{2}{|c|}{ HE grade } & \multirow[t]{2}{*}{ Clinical outcome } \\
\hline & & & Pre & Post & & & Pre & Post & \\
\hline $1 / 54$ & $\begin{array}{l}10 \times 8+2 \mathrm{~cm} \\
\text { Viatorr }\end{array}$ & $5 \times 15$; Palmaz Blue & 5 & 12 & Successful & Increased & II & IV & Died $^{\text {a }}$; recurrent GIH \\
\hline $2 / 55$ & $\begin{array}{l}10 \times 6+2 \mathrm{~cm} \\
\text { Viatorr }\end{array}$ & $5 \times 15$; Palmaz Blue & 7 & 10 & Successful & Unchanged & II & None & Alive; no complications \\
\hline $3 / 55$ & $\begin{array}{l}10 \times 8+2 \mathrm{~cm} \\
\text { Viatorr }\end{array}$ & $5 \times 18$; Palmaz Blue & 3 & 10 & Successful & Unchanged & IV & IV & Died $^{\text {b }}$; recurrent GIH \\
\hline $4 / 64$ & $\begin{array}{l}10 \times 7+2 \mathrm{~cm} \\
\text { Viatorr }\end{array}$ & $\begin{array}{l}5 \times 18 ; \text { Palmaz } \\
\text { Genesis }\end{array}$ & 4 & 6 & Successful & Unchanged & III & None & Alive; no complications \\
\hline $5 / 53$ & $\begin{array}{l}10 \times 7+2 \mathrm{~cm} \\
\text { Viatorr }\end{array}$ & $5 \times 18$; Palmaz Blue & 6 & 13 & Successful & Unchanged & III & II & Alive; no complications \\
\hline $6 / 70$ & $\begin{array}{l}10 \times 7+2 \mathrm{~cm} \\
\text { Viatorr }\end{array}$ & $6 \times 18$; Palmaz Blue & 0 & 8 & Successful & Increased & IV & None & $\begin{array}{l}\text { Alive }^{c} ; \text { no } \\
\text { complications }\end{array}$ \\
\hline $7 / 45$ & $\begin{array}{l}10 \times 7+2 \mathrm{~cm} \\
\text { Viatorr }\end{array}$ & $6 \times 12$; Palmaz Blue & 12 & 18 & Successful & Unchanged & II & II & Alive; recurrent GIH \\
\hline $8 / 61$ & $\begin{array}{l}10 \times 6+2 \mathrm{~cm} \\
\text { Viatorr }\end{array}$ & $6 \times 18$; Palmaz Blue & 2 & 7 & Successful & Increased & I & None & Alive; no complications \\
\hline
\end{tabular}

GIH gastrointestinal hemorrhage

a Hepatic failure

b Hepatic and renal failure

${ }^{c}$ Underwent liver transplantation

[10]. By using a balloon-expandable stent to extrinsically narrow an adjacent stent graft, the parallel technique optimizes control of TIPS configuration and flow, potentially favoring this method in comparison with alternative procedures.

The findings of this study confirm the reproducibility and high technical success rate of the parallel technique. A dual unilateral transjugular approach was successful in all cases and allowed accurate and reliable positioning of the stent graft and stent. A combined transjugular and transfemoral approach is an alternative, but TIPS catheterization via the transfemoral route is less anatomically favorable and may not be possible [4]. The use of two remote sites of venous access also increases the technical difficulty of this procedure for a single operator and may require two operators to successfully perform the technique. Dual unilateral access via the right internal jugular vein is straightforward and is suggested as the first-line approach to this procedure. A left-sided transjugular approach is also feasible if required.

TIPS reduction was beneficial in most patients, with clinical improvement $(62.5 \%)$ and resolution (50\%) of HE, comparable with previous results that used the parallel technique [4]. Overall clinical outcomes were not, however, universally favorable. In accordance with previous findings [19, 20], the occurrence of persistently severe or progressive postprocedural encephalopathy was associated with significant morbidity and mortality. Liver transplantation remains a potentially definitive treatment option in these circumstances but was not appropriate for the patients with refractory hepatic failure in this study. An increased risk of complications of portal hypertension is also expected after TIPS reduction. Routine periprocedural endoscopy is therefore recommended in all patients with a history of varices to minimize the incidence of recurrent gastrointestinal hemorrhage. The 3 patients $(37.5 \%)$ in this study with recurrent hemorrhage were successfully treated by conservative management and were not referred for TIPS reevaluation. Shunt redilatation may have provided effective treatment of rebleeding in these cases, although it is likely to have worsened the HE. Endoscopic assessment is therefore also recommended in this setting before consideration of TIPS adjustment.

TIPS reintervention was not undertaken in the patients in this study. Repeat TIPS reduction with dead-space embolization was, however, performed in another patient with a 12-mm-diameter uncovered TIPS (Wallstent; Boston Scientific, MA) who had continued perfusion of the old shunt after the first reduction procedure. This was technically successful, confirming the feasibility of repeat TIPS reduction by reiteration of the parallel technique. Positioning the balloon-expandable stent at the cephalad end of the shunt, rather than at its midportion, has recently been suggested as a further modification of the parallel 
technique in order to simplify interval TIPS adjustment [9]. This has the potential advantage of preserving access to the original balloon-expandable stent, thereby allowing interval TIPS reduction without requiring complete reiteration of the procedure. Access to the stent graft for shunt redilatation may, however, be comparatively more difficult using this method.

The optimum procedural end point of TIPS reduction is uncertain and may vary between patients. An increase in PSPG was used as the end point in this study and was achieved in all patients. The mean increase in PSPG and final PSPG values were similar to those obtained by Maleux et al., who used a slightly larger (6-7 mm diameter) balloon-expandable stent [4]. Increasing antegrade intrahepatic portal perfusion may be more relevant as an end point to an improvement in mental status than increasing PSPG per se [3, 4, 9]. Immediate angiographic changes in intrahepatic portal perfusion were not consistently observed in this study and may in general require substantially higher PSPG values in order to be reliably achieved [9]. In accordance with previous observations [4], however, there was no clear correlation between changes in either PSPG or intrahepatic portal perfusion and changes in HE grade in the small number of patients in this study. The optimum PSPG in terms of rebleeding risk in patients with varices is also uncertain. Two patients (67\%) with recurrent bleeding in this study had a final PSPG of $\leq 12 \mathrm{mmHg}$. A postreduction PSPG within this conventional target range may not therefore confer safety from rebleeding. Conversely, a PSPG $>12 \mathrm{mmHg}$ may be acceptable in patients with varices if TIPS reduction is coupled with endoscopic intervention and/or embolization [9]. Additional investigation is required to further define the end points of TIPS reduction associated with optimum clinical outcome, acknowledging that shunt adjustment may be of limited therapeutic benefit in the presence of advanced hepatic failure.

There are several limitations of this study. The number of patients was small, precluding detailed statistical analysis of data. Investigation was retrospective and the duration of clinical follow-up was short. Formal assessment of shunt patency and PSPG after TIPS reduction was also limited to the intraprocedural period.

In conclusion, the parallel technique is a reproducible method of TIPS reduction and has a high technical success rate. A dual unilateral transjugular approach is advantageous when performing this procedure. The parallel technique allows repeat bidirectional TIPS adjustment and may be of significant clinical benefit in the management of refractory HE. Additional investigation is required to further define the end points of TIPS reduction associated with optimum clinical outcome.
Conflict of interest The authors declare that they have no conflict of interest.

\section{References}

1. Zuckerman DA, Darcy MD, Bocchini TP et al (1997) Encephalopathy after transjugular intrahepatic portosystemic shunting: analysis of incidence and potential risk factors. AJR Am J Roentgenol 169:1727-1731

2. Forauer AR, Mclean GK (1998) Transjugular intrahepatic portosystemic shunt constraining stent for the treatment of refractory postprocedural encephalopathy: a simple design utilizing a Palmaz stent and Wallstent. J Vasc Interv Radiol 9:443-446

3. Madoff DC, Wallace MJ, Ahrar K et al (2004) TIPS-related hepatic encephalopathy: management options with novel endovascular techniques. Radiographics 24:21-37

4. Maleux G, Heye S, Verslype C, Nevens F (2007) Management of transjugular portosystemic shunt-induced refractory hepatic encephalopathy with the parallel technique: results of a clinical follow-up study. J Vasc Interv Radiol 18:986-9935

5. Holden A, Ng R, Gane E et al (2006) A technique for controlled partial closure of a transjugular intrahepatic portosystemic shunt tract in a patient with hepatic encephalopathy. J Vasc Interv Radiol 17:1957-1961

6. Saket R, Sze D, Razavi M et al (2004) TIPS reduction with use of stents or stent-grafts. J Vasc Interv Radiol 15:745-751

7. Maleux G, Verslype C, Heye S et al (2007) Endovascular shunt reduction in the management of transjugular portosystemic shuntinduced hepatic encephalopathy: preliminary experience with reduction stents and stent-grafts. AJR Am J Roentgenol 188: 659-664

8. Quaretti P, Michieletti E, Rossi S (2001) Successful treatment of TIPS-induced hepatic failure with an hourglass stent-graft: a simple new technique for reducing shunt flow. J Vasc Interv Radiol 12:887-890

9. Sze DY, Hwang GL, Kao JS et al (2008) Bidirectionally adjustable TIPS reduction by parallel stent and stent-graft deployment. J Vasc Interv Radiol 19:1653-1658

10. Kroma G, Lopera J, Cura M et al (2009) Transjugular intrahepatic portosystemic shunt flow reduction with adjustable polytetrafluoroethylene-covered balloon-expandable stents. J Vasc Interv Radiol 20:981-986

11. Madoff DC, Perez-Young IV, Wallace MJ et al (2003) Management of TIPS-related refractory hepatic encephalopathy with reduced Wallgraft endoprostheses. J Vasc Interv Radiol 14:369-374

12. Ferenci P, Lockwood A, Mullen K et al (2002) Hepatic encephalopathy-definition, nomenclature, diagnosis and quantification: final report of the Working Party at the 11th World Congresses of Gastroenterology, Vienna, 1998. Hepatology 35: 716-721

13. Paz-Fumagalli R, Crain MR, Mewissen MW et al (1994) Fatal hemodynamic consequences of therapeutic closure of a transjugular portosystemic shunt. J Vasc Interv Radiol 5:831-834

14. Haskal ZJ, Cope C, Soulen MC et al (1995) Intentional reversible thrombosis of transjugular intrahepatic portosystemic shunts. Radiology 195:485-488

15. Kerlan RK Jr, LaBerge JM, Baker EL (1995) Successful reversal of hepatic encephalopathy with intentional occlusion of transjugular intrahepatic portosystemic shunts. J Vasc Interv Radiol 6:917-921

16. Kochar N, Tripathi D, Ireland $\mathrm{H}$ et al (2006) Transjugular intrahepatic portosystemic shunt (TIPSS) modification in the 
management of post-TIPSS refractory hepatic encephalopathy. Gut 55:1617-1623

17. Haskal ZJ, Middlebrook MR (1994) Creation of stenotic stent to reduce flow through a transjugular intrahepatic portosystemic shunt. J Vasc Interv Radiol 5:827-830

18. Gerbes AL, Waggershauser T, Holl J et al (1998) Experiences with novel techniques for reduction of stent flow in transjugular intrahepatic portosystemic shunts. Z Gastroenterol 36:373-377
19. Rouillard SS, Bass NM, Roberts JP et al (1998) Severe hyperbilirubinemia after creation of transjugular intrahepatic portosystemic shunts: natural history and predictors of outcome. Ann Intern Med 128:374-377

20. Barton RE, Rosch J, Saxon RR et al (1995) TIPS: short and longterm results: a survey of 1750 patients. Semin Interv Radiol $12: 364-369$ 